\title{
АДДИКТИВНАЯ ИДЕНТИЧНОСТЬ: СТРУКТУРНО-КРИТЕРИАЛЬНЫЙ АСПЕКТ
}

\author{
(С) Иванова Н.Л. , Никишина В.Б. ${ }^{2}$, Петраш Е.А. ${ }^{2}$ Верес И. ${ }^{3}$ \\ ${ }^{1}$ Научно-исследовательский университет «Высшая школа экономики», Москва; \\ ${ }^{2}$ Курский государственный медицинский университет, Курск; \\ ${ }^{3}$ Неврологический психиатрический центр Верес Клиник, Ларнака, Республика Кипр \\ E-mail: petrash@mail.ru
}

\begin{abstract}
Реализовано эмпирическое исследование критериев аддиктивной идентичности при химической (алкогольная, наркотическая зависимость, зависимость от курительных смесей) и физической (игровая зависимость) зависимости. Представлены результаты сравнительного анализа критериев аддиктивной идентичности в параметрах согласованности / рассогласованности, адаптивности / неадаптивности, самоактуализации / нарушения самоактуализации, ответственности / безответственности, совестливости / бессовестливости, конструктивности / деструктивности. В результате исследования установлено, что аддиктивная идентичность на структурном уровне вне зависимости от объекта зависимости характеризуется рассогласованностью структурной организации, проявляющейся в низком уровне выраженности социально-психологической адаптации, неустойчивости системы ценностных ориентаций, низком уровне рефлексивности и самостоятельности.
\end{abstract}

Ключевые слова: аддиктивная идентичность, критерии аддиктивной идентичности, рассогласованность, дезадаптивность, нарушение самоактуализации, безответственность, бессовестливость, деструктивность.

\section{ADDICTIVE IDENTITY: STRUCTURAL AND CRITERION ASPECT Ivanova N.L. ${ }^{1}$, Nikishina V.B. ${ }^{2}$, Petrash E.A. ${ }^{2}$, Veres I. ${ }^{3}$}

${ }^{1}$ National Research University "Higher School of Economics", Moscow; ${ }^{2}$ Kursk State Medical University, Kursk; ${ }^{3}$ Veresies Clinic, Larnaca, Republic of Cyprus

The addictive identity criteria in chemical (alcohol, drug addiction, smoking mixtures dependence) and physical (gambling addiction) dependence were empirically studied. The results of the comparative analysis of the addictive identity criteria were represented according to the following parameters: consistency / inconsistency, adaptability / non-adaptability, selfactualization / disorders of self-actualization, responsibility / irresponsibility, conscientiousness / unconscientiousness, constructiveness / destructiveness. The study found that the addictive identity at the structural level, regardless of the dependency object, is characterized by inconsistency of the structural organization manifested itself in the low level of social and psychological adaptation, the instability of value orientations, and a low level of reflexivity and self-reliance.

Keywords: addictive identity, addictive identity criteria, inconsistency, maladaptive, disordres of self-actualization, irresponsibility, unconscientiousness, destructiveness.

Актуальность исследования аддиктивной идентичности, представляющей собой нарушение социальной идентичности, в структурнокритериальном аспекте обусловлена с одной стороны увеличением своей распространенности и дифференцированности в условиях современной реальности. С другой - возрастание распространенности и дифференцированности феномена аддиктивной идентичности сопровождается невысокой исследовательской активностью типичности и специфичности проявлений данного феномена. Осуществив запрос в системе научной электронной библиотеке eLibrary по ключевым словам «социальная идентичность», за период 2006-2016 очевидно фиксируем противоречие: за последние 10 лет количество научных публикаций увеличилось в 7,8 раза, а количество исследований по всем видам нарушений идентичности (аддиктивной, делинквентной и т.д.) составляет не более 1\% (работы Злоказова К.В., 2015; Руденского Е.В. и др., 2015; Мякотина И.С., 2015; Суворо- вой И.Ю., 2016; Reith G., 2004; Litt M. D. et al., 2015; Beckwith M. et al., 2015) [4, 5, 12, 13, 14, 15, $16]$.

На теоретическом уровне проявляется тенденция отсутствия согласованности критериев нарушения социальной идентичности при многообразии теорий и подходов к изучению феномена социальной идентичности (психодинамический подход; когнитивно-бихевиоральный подход; структурный подход; феноменологический подход. Изучению нарушений социальной идентичности посвящены работы К.В. Злоказова (2015); Е.В. Руденского и др. (2015) и т.д. [3, 4, 5, 14-16].

Обобщая и систематизируя опыт критеризации нормы и нарушения психологического, нами сформирован в дихотомической логике перечень критериев, которые соотнесены в свою очередь с идеей дифференциации нарушений социальной идентичности по отношению к реальности [7]. Таким образом, выделены три группы нарушений социальной идентичности: нарушение социаль- 
ной идентичности как уход от социальной реальности (аддиктивная идентичность); нарушение социальной идентичности как противостояние социальной реальности (делинквентная идентичность); нарушение социальной идентичности как приспособление к социальной реальности (при соматической патологии). Аддиктивная идентичность как нарушение социальной идентичности характеризуется способом ухода от реальности, проявляется как на уровне структуры диффузностью и дезорганизованностью $[1,2,6,8$, 10], так и на уровне критериально-феноменологическом: рассогласованностью структурной организации; дезадаптивностью; нарушением самоактуализации; безответственностью; бессовестливостью (лживостью); деструктивностью.

В научных работах аддиктивное поведение и аддиктивную идентичность дифференцируют по объекту зависимости с выделением химического и физического вариантов, при том, что каждая из групп имеет внутреннюю дифференциацию: химическая зависимость включает в себя алкогольную, наркотическую зависимость, зависимость от курительных смесей; физическая зависимость включает игровую, компьютерную зависимость и др.
Критериальный подход к социальной идентичности формировался на теоретических положениях К.К. Платонова (1986) [11], который выделил критерии нормы/отклонения: согласованность / рассогласованность, адаптивность / неадаптивность, самоактуализация / нарушение самоактуализации, ответственность / безответственность, совестливость / бессовестливость, конструктивность / деструктивность (табл. 1).

Целью исследования является критериальная оценка аддиктивной идентичности.

\section{МАТЕРИАЛЫ И МЕТОДЫ ИССЛЕДОВАНИЯ}

Общий объем выборки составил 239 человек (128 мужчин и 111 женщин) в возрасте 26-54 года (средний возраст составил $35,14 \pm 4,62$ года). В экспериментальную группу вошли 189 человек с аддикцией. В контрольную группу вошли 50 испытуемых, имеющих заключение «здоров» по результатам прохождения процедуры профосмотра и психологического исследования структурной организации социальной идентичности.

Таблица 1

Критерии нормы-нарушения социальной идентичности: содержательно-методический анализ

\begin{tabular}{|c|c|c|}
\hline Критерий & Характеристика & $\begin{array}{c}\text { Инструментально-диагностическое содержание } \\
\text { критерия }\end{array}$ \\
\hline $\begin{array}{l}\text { Согласованность / } \\
\text { рассогласованность }\end{array}$ & $\begin{array}{c}\text { Системное свойство, } \\
\text { характеризующееся } \\
\text { соотнесенностью структурных } \\
\text { компонентов идентичности в их } \\
\text { взаимосвязях. }\end{array}$ & $\begin{array}{c}\text { Методика исследования структурной } \\
\text { организации личностной идентичности } \\
\text { (МИСОЛИ) (Никишина В.Б., Петраш Е.А.). } \\
\text { Высокая, средняя, низкая, очень низкая степень } \\
\text { согласованности структурой организации } \\
\text { идентичности. }\end{array}$ \\
\hline $\begin{array}{l}\text { Адаптивность / } \\
\text { неадаптивность }\end{array}$ & $\begin{array}{c}\text { Свойство системы, проявляющееся } \\
\text { в способности к изменениям в } \\
\text { соответствии с требованиями } \\
\text { внешней социальной ситуации. }\end{array}$ & $\begin{array}{c}\text { Опросник социально-психологической } \\
\text { адаптации (Роджерс К., Даймонд Р.) } \\
\text { Адаптивность. }\end{array}$ \\
\hline $\begin{array}{l}\text { Самоактуализация / } \\
\text { нарушение } \\
\text { самоактуализации }\end{array}$ & $\begin{array}{c}\text { Свойство, проявляющееся в } \\
\text { стремлении к возможно более } \\
\text { полному выявлению и развитию } \\
\text { своих потребностей и } \\
\text { возможностей. }\end{array}$ & $\begin{array}{c}\text { Опросник самоактуализации (Шостром Э.). } \\
\text { Ориентация во времени, самоуважение, } \\
\text { креативность. }\end{array}$ \\
\hline $\begin{array}{l}\text { Ответственность / } \\
\text { безответственность }\end{array}$ & $\begin{array}{c}\text { Свойство, проявляющееся в } \\
\text { способности отвечать за свои } \\
\text { действия и поступки и их } \\
\text { моральная оценка. }\end{array}$ & $\begin{array}{c}\text { Методика диагностики уровня морально- } \\
\text { этической ответственности личности } \\
\text { (ДУМЭОЛ) (Муздыбаев К.К.) } \\
\text { Общий уровень морально-этической } \\
\text { ответственности. }\end{array}$ \\
\hline $\begin{array}{c}\text { Совестливость / } \\
\text { бессовестливость } \\
\text { (лживость) }\end{array}$ & $\begin{array}{c}\text { Свойство принимать } \\
\text { ответственность за свои действия } \\
\text { и поступки. } \\
\end{array}$ & $\begin{array}{c}\text { Методика определения склонности ко лжи } \\
\text { (Экман П.) } \\
\text { Уровень склонности ко лжи. }\end{array}$ \\
\hline $\begin{array}{l}\text { Конструктивность / } \\
\text { деструктивность }\end{array}$ & $\begin{array}{c}\text { Свойство, проявляющееся в } \\
\text { отсутствии направленности на } \\
\text { причинение вреда другим или } \\
\text { себе. }\end{array}$ & $\begin{array}{c}\text { Шкала враждебности (Кука-Медлей) } \\
\text { Враждебность. }\end{array}$ \\
\hline
\end{tabular}


В соответствии с целью исследования экспериментальная группа была разделена на четыре исследовательские выборки по критерию объекта зависимости: 55 человек с алкогольной зависимостью (F10.2 «Психические и поведенческие расстройства, вызванные употреблением алкоголя - синдром зависимости» по МКБ-10); 41 человек c наркотической (опиоидной) зависимостью (F11.2 «Психические и поведенческие расстройства, вызванные употреблением опиоидов синдром зависимости» по МКБ-10); 39 человек с зависимостью от курительных смесей (F19.2 «Психические и поведенческие расстройства, вызванные одновременным употреблением нескольких наркотических средств и использованием других психоактивных веществ - синдром зависимости» по МКБ-10); 54 человека с игровой зависимостью (F63.0 «Патологическое влечение к азартным играм» по МКБ-10). Эмпирическое исследование осуществлялось на базе Курского областного наркологического диспансера на условиях информированного согласия.

Количественная и качественная обработка полученных эмпирических данных осуществлялась с использованием методов описательной (показатели средних значений, среднее квадратическое отклонение), сравнительной статистики - непараметрических критериев (U-критерий Манна-Уитни); многомерной статистики (факторный анализ c varymax-вращением).

Организация исследования осуществлялась последовательно в два этапа. На первом этапе осуществлялась количественно-качественная оценка структуры и критериев нарушения социальной идентичности при аддикции (через попарное сравнение каждого вида зависимости с группой нормы). Завершающим этапом исследования являлась оценка факторной структуры кри- териев аддиктивной идентичности с учетом объекта зависимости.

\section{РЕЗУЛЬТАТЫ ИССЛЕДОВАНИЯ И ИХ ОБСУЖДЕНИЕ}

Анализируя полученные результаты, установлено, что безотносительно объекта зависимости на уровне критериальных оценок выявлен низкий уровень согласованности-рассогласованности структурной организации аддиктивной идентичности в сравнении с группой нормы (рис. 1).

Рассогласованность структурной организации аддиктивной идентичности как при химической, так и при нехимической зависимости характеризуется низким уровнем выраженности социальнопсихологической адаптации, неустойчивостью системы ценностных ориентаций, а также низким уровнем рефлексивности и самостоятельности [9].

При исследовании критериев проявления аддиктивной идентичности вне зависимости от объекта типизирующими проявлениями являются бессовестливость, проявляющаяся в высокой склонности ко лжи; дезадаптивность, проявляющаяся в общей дезадаптивности и непринятии других;нарушение самоактуализации, проявляющееся во временной дезориентации, ригидности поведения и низкой сензитивности; а также деструктивность, проявляющаяся в высоком уровне враждебности (таблица 2).

Специфизирующимипроявлениями критериев аддиктивной идентичности при алкогольной зависимости являются низкий уровень эмоционального комфорта, интернальности и доминирования, раскрывающие содержание критерия неадаптивности.

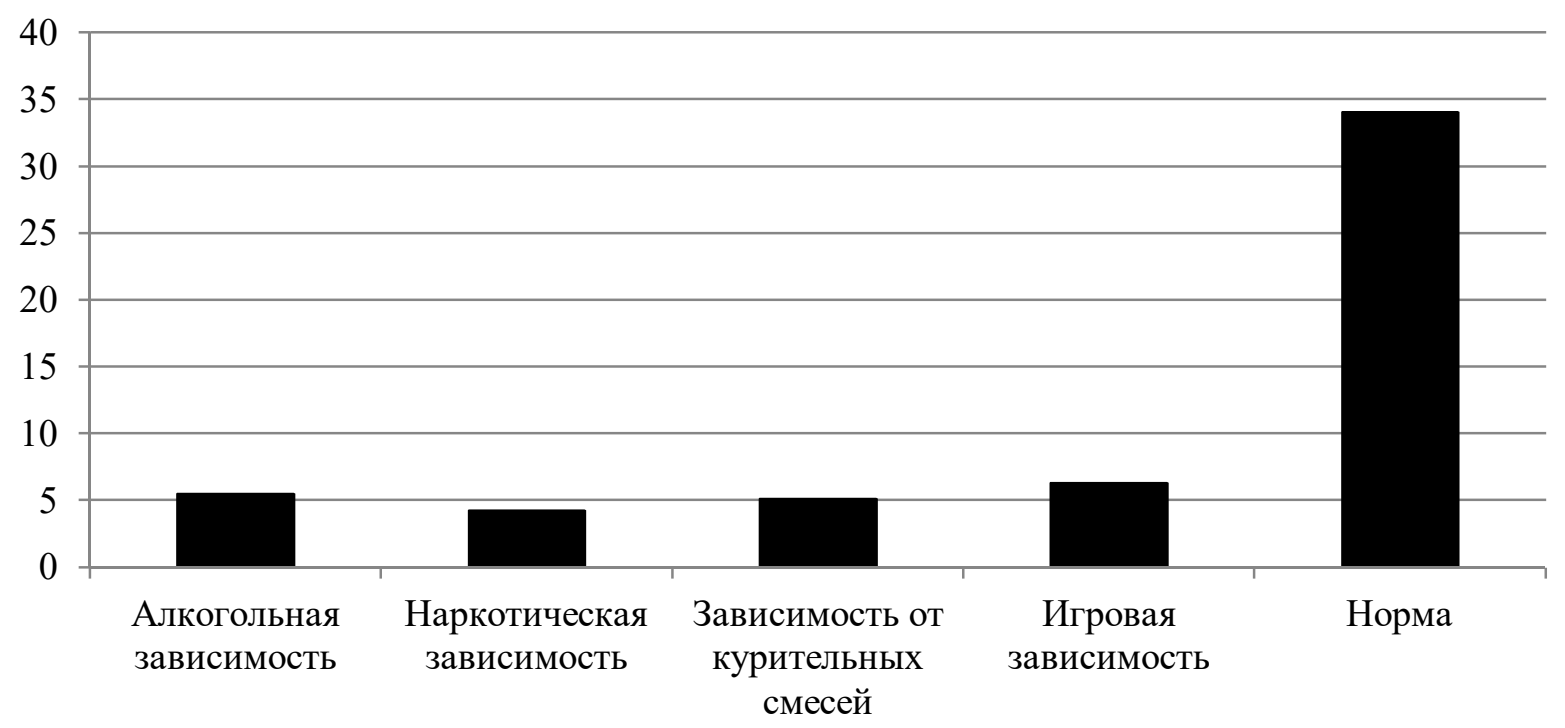

Рис. 1. Гистограмма значений согласованности-рассогласованности структуры аддиктивной идентичности по объекту зависимости. 
Показатели средних значений критериев аддиктивной идентичности $(\mathrm{x} \pm \sigma)$

\begin{tabular}{|l|c|c|c|c|}
\hline \multirow{2}{*}{ Критериальное содержание } & \multicolumn{4}{|c|}{ Показатель средних значений } \\
\cline { 2 - 5 } & $\begin{array}{c}\text { Алкогольная } \\
\text { зависимость }\end{array}$ & $\begin{array}{c}\text { Наркотическая } \\
\text { зависимость }\end{array}$ & $\begin{array}{c}\text { Зависимость от } \\
\text { курительных смесей }\end{array}$ & $\begin{array}{c}\text { Игровая } \\
\text { зависимость }\end{array}$ \\
\hline $\begin{array}{l}\text { Согласованность структурной } \\
\text { организации }\end{array}$ & $12,6 \pm 2,18$ & $9,34 \pm 1,92$ & $13,1 \pm 3,16$ & $12,9 \pm 2,57$ \\
\hline Адаптивность & $37,54 \pm 3,26$ & $31,48 \pm 3,54$ & $34,52 \pm 2,96$ & $36,78 \pm 4,12$ \\
\hline Ориентация во времени & $7,6 \pm 1,92$ & $5,16 \pm 1,54$ & $6,29 \pm 1,73$ & $7,12 \pm 2,05$ \\
\hline Самоуважение & $8,21 \pm 1,96$ & $6,34 \pm 2,15$ & $6,98 \pm 2,54$ & $7,14 \pm 2,68$ \\
\hline Креативность & $7,4 \pm 2,12$ & $5,69 \pm 1,37$ & $6,12 \pm 2,44$ & $6,94 \pm 2,15$ \\
\hline $\begin{array}{l}\text { Морально-этическая } \\
\text { ответственность }\end{array}$ & $12,42 \pm 2,19$ & $10,34 \pm 2,57$ & $11,02 \pm 2,30$ & $11,38 \pm 2,54$ \\
\hline Склонность ко лжи & $6,2 \pm 0,94$ & $4,7 \pm 0,49$ & $5,18 \pm 1,06$ & $5,82 \pm 1,14$ \\
\hline Враждебность & $26,1 \pm 4,59$ & $28,05 \pm 5,83$ & $27,16 \pm 6,14$ & $26,92 \pm 6,12$ \\
\hline
\end{tabular}

Алкогольная зависимость

Враждебность

Склонность ко лжи

Морально-этическая ответственность

Креативность

Самоуважение

Ориентация во времени

Адаптивность

Согласованность

структурной организации

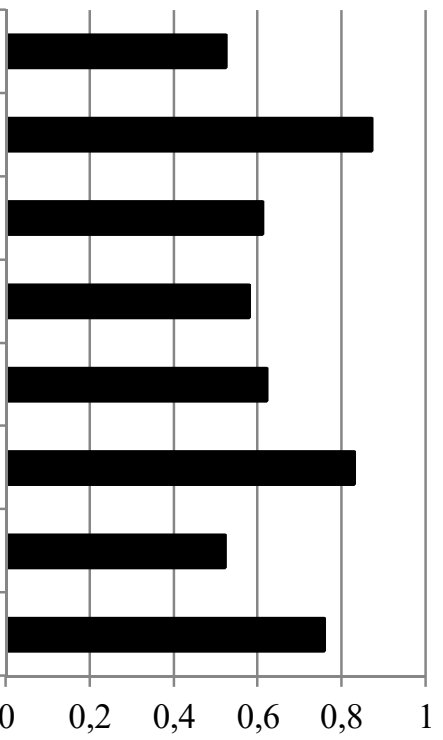

Зависимость от курительных смесей

Враждебность

Склонность ко лжи

Морально-этическая ответственность

Креативность

Самоуважение

Ориентация во времени

Адаптивность

Согласованность структурной организации

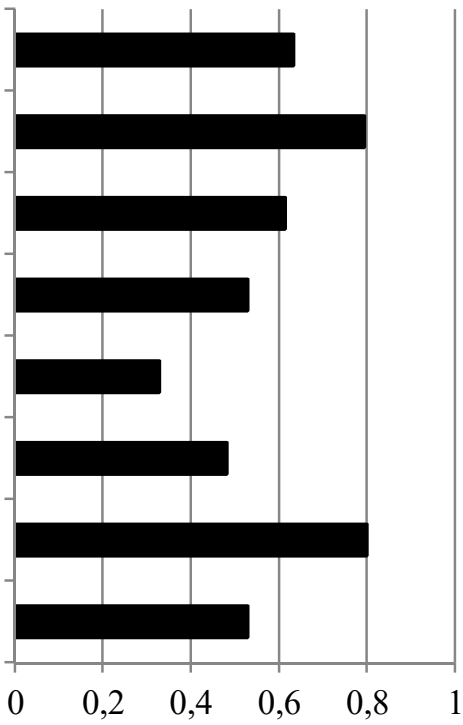

Наркотическая зависимость

Враждебность

Склонность ко лжи

Морально-этическая ответственность

Креативность

Самоуважение

Ориентация во времени

Адаптивность

Согласованность

структурной организации

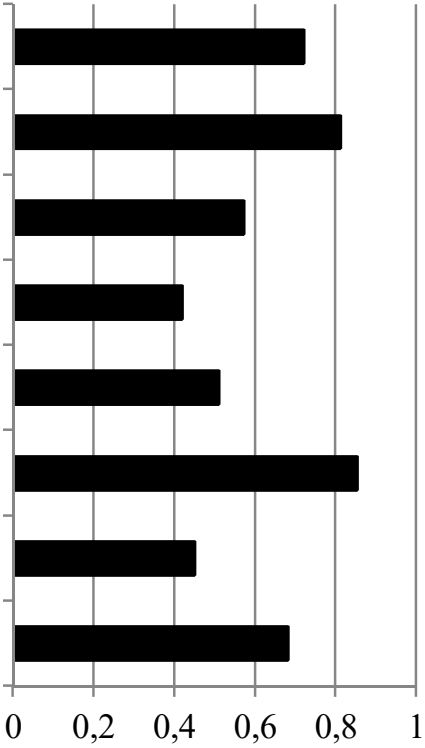

Игровая зависимость

Враждебность

Склонность ко лжи

Морально-этическая ответственность

Креативность

Самоуважение

Ориентация во времени

Адаптивность

Согласованность структурной организации
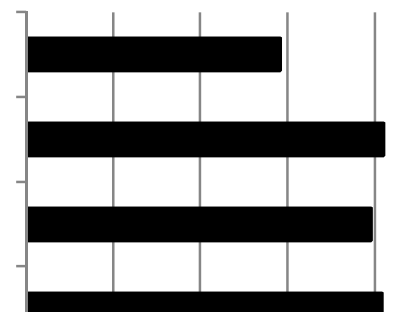

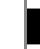

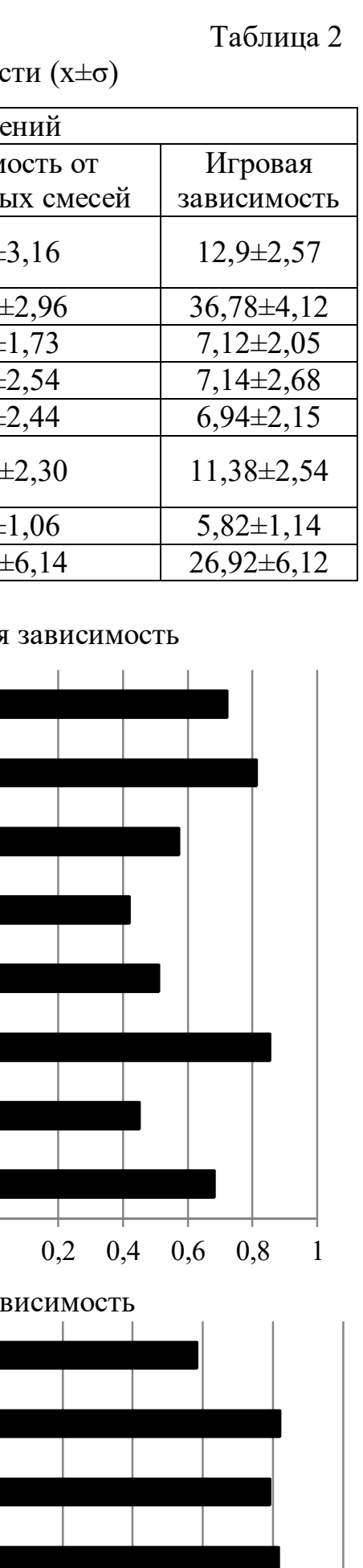


Эмпирическое обобщение критериев аддиктивной идентичности

\begin{tabular}{|c|c|c|c|c|}
\hline \multirow[b]{2}{*}{ Критерии } & \multicolumn{3}{|c|}{ Химическая зависимость } & \multirow{2}{*}{$\begin{array}{c}\text { Игровая } \\
\text { зависимость }\end{array}$} \\
\hline & $\begin{array}{c}\text { Алкогольная } \\
\text { зависимость }\end{array}$ & $\begin{array}{c}\text { Наркотическая } \\
\text { зависимость }\end{array}$ & $\begin{array}{c}\text { Зависимость от } \\
\text { курительных смесей }\end{array}$ & \\
\hline $\begin{array}{c}\text { Адаптивность / } \\
\text { дезадаптивность }\end{array}$ & $\begin{array}{c}\text { Низкий уровень } \\
\text { социально- } \\
\text { психологической } \\
\text { адаптации, } \\
\text { проявляющийся в } \\
\text { непринятии других, } \\
\text { экстернальности } \\
\text { при эмоциональном } \\
\text { комфорте. }\end{array}$ & $\begin{array}{c}\text { Низкий уровень } \\
\text { социально- } \\
\text { психологиче- } \\
\text { ской адаптации, } \\
\text { проявляющийся } \\
\text { в непринятии } \\
\text { себя и других, } \\
\text { интернальности. }\end{array}$ & $\begin{array}{c}\text { Низкий уровень } \\
\text { социально- } \\
\text { психологической } \\
\text { адаптации, } \\
\text { проявлящийся в } \\
\text { непринятии себя и } \\
\text { других, } \\
\text { интернальности, } \\
\text { эмоциональном } \\
\text { комфорте. }\end{array}$ & $\begin{array}{c}\text { Низкий уровень } \\
\text { социально- } \\
\text { психологической } \\
\text { адаптации, } \\
\text { проявляющийся в } \\
\text { стремлении к } \\
\text { доминированию, } \\
\text { принятии других, } \\
\text { экстернальности. }\end{array}$ \\
\hline $\begin{array}{c}\text { Самоактуализация / } \\
\text { нарушение }\end{array}$ & \multicolumn{4}{|c|}{$\begin{array}{c}\text { Нарушение самоактуализации проявляется в дезориентации во времени, ригидности } \\
\text { поведения, низкой сензитивности по отношению к окружающим. }\end{array}$} \\
\hline \multirow[t]{2}{*}{ самоактуализации } & $\begin{array}{c}\text { Низкая } \\
\text { сензитивность по } \\
\text { отношению к себе. }\end{array}$ & $\begin{array}{c}\text { Высокий } \\
\text { уровень } \\
\text { принятия } \\
\text { агрессии, низкая } \\
\text { синергия. }\end{array}$ & \multirow{2}{*}{\multicolumn{2}{|c|}{$\begin{array}{c}\text { Высокое самоуважение, выраженность } \\
\text { познавательных потребностей, } \\
\text { креативности в поиске объекта } \\
\text { удовлетворения патологического влечения. }\end{array}$}} \\
\hline & \multicolumn{2}{|c|}{$\begin{array}{l}\text { Отсутствие познавательной } \\
\text { потребности и креативности. }\end{array}$} & & \\
\hline $\begin{array}{l}\text { Ответственность / } \\
\text { безответственность }\end{array}$ & \multicolumn{4}{|c|}{$\begin{array}{c}\text { Низкий уровень морально-этической ответственности, проявляющийся в снижении } \\
\text { альтруистических эмоций и морально-этических ценностей. }\end{array}$} \\
\hline $\begin{array}{c}\text { Совестливость / } \\
\text { бессовестливость }\end{array}$ & \multicolumn{4}{|c|}{ Высокий уровень склонности ко лжи. } \\
\hline $\begin{array}{c}\text { Конструктивность / } \\
\text { деструктивность }\end{array}$ & \multicolumn{2}{|c|}{$\begin{array}{c}\text { Высокий уровень враждебности и } \\
\text { агрессивности. }\end{array}$} & \multicolumn{2}{|c|}{ Высокий уровень враждебности и цинизма. } \\
\hline
\end{tabular}

Нарушение самоактуализации как критерий аддиктивной идентичности при алкогольной зависимости реализуется в низком самоуважении, а также отсутствии познавательных потребностей и креативности. Специфическими проявлениями критериев аддиктивной идентичности при наркотической зависимости являются низкая синергия, проявляющаяся в нарушении целостности восприятия мира и себя, а также высокий уровень принятия агрессии как содержание критерия нарушения самоактуализации (таблица 3 ).

При зависимости от курительных смесей специфическими проявлениями критериев аддиктивной идентичности являются высокое самоуважение, а также выраженные познавательные потребности и креативность в поиске объекта удовлетворения патологического влечения как содержание критерия нарушения самоактуализации. При игровой зависимости специфическим проявлением на уровне содержания критерия неадаптивности является стремление к доминированию и экстернальность; на уровне критерия нарушения самоактуализации - высокое самоуважение и выраженность познавательных потребностей.
Для определения иерархичности в распределении критериев аддиктивной идентичности осуществлялась оценка факторной структуры критериев аддиктивной идентичности с учетом объекта зависимости с использованием метода факторного анализа с varymax-вращением $(\mathrm{p}<0,05)$. Для графического представления полученных результатов использовались значения показателей первого фактора с основной факторной нагрузкой (рис. 2).

При алкогольной зависимости факторная структура критериев аддиктивной идентичности характеризуется преобладанием склонности ко лжи, дезориентацией во времени как проявлением нарушения самоактуализации, что обеспечивает дезинтегрированность структурной организации аддиктивной идентичности. При наркотической зависимости в факторной структуре преобладающими являются критерий бессовестливости (проявляющийся в склонности ко лжи), враждебности, а также нарушения самоактуализации (проявляющийся в дезориентации во времени). При зависимости от курительных смесей в качестве ключевых критериев аддиктивной идентичности, характеризующейся дезинтегрированностью 
структурной

организации,

выступают

бессовестливость и дезадаптивность. При игровой зависимости рассогласованность структурной организации аддиктивной идентичности реализуется в критериальных оценках бессовестливости (проявляющейся в склонности ко лжи), безответственности, а также нарушении самоактуализации, проявляющемся через показатель креативности.

Аддиктивная идентичность на структурном уровне вне зависимости от объекта зависимости характеризуется рассогласованностью структурной организации, проявляющейся в низком уровне выраженности социально-психологической адаптации, рефлексивности и самостоятельности, а также неустойчивости системы ценностных ориентаций. Типизирующими критериями аддиктивной идентичности при химической и физической зависимости выступают бессовестливость (как склонность ко лжи), нарушение самоактуализации, а также деструктивность как проявление враждебности.

Специфизирующими критериями аддиктивной идентичности при алкогольной зависимости являются низкий уровень принятия других, эмоциональный дискомфорт, интернальность, отсутствие стремления к доминированию, характеризующие содержание критерия неадаптивности; низкое самоуважение, отсутствие познавательных потребностей и креативности, характеризующие нарушение самоактуализации. При наркотической зависимости специфизирующими критериями аддиктивной идентичности являются низкая синергия и высокий уровень принятия агрессии как содержание критерия нарушения самоактуализации. При зависимости от курительных смесей специфизирующими критериями аддиктивной идентичности являются высокое самоуважение при выраженных познавательных потребностях и креативности, характеризующих нарушение самоактуализации. Специфизирующими критериями аддиктивной идентичности при игровой зависимости являются стремление к доминированию и экстернальность как проявления неадаптивности; высокое самоуважение, креативность и выраженность познавательных потребностей как проявления нарушения самоактуализации.

\section{ЛИТЕРАТУРА}

1. Бохан Н.А. Нейробиологические проблемы изучения аддиктивных расстройств (обзор региональных исследований // Сибирский вестник психиатрии и наркологии. - 2008. - № 1. - С. 59-62.

2. Дмитриева Н.В., Дубровина О.В. Аддиктивная идентичность виртуально зависимой личности. -
Ишим : Изд-во Ишимского гос. педагогического института, 2010. - 200 с.

3. Дубровина O.B. Структурно-содержательные характеристики Я-концепции личности с виртуальной аддикцией // Педагогическое образование и наука. - 2009. - № 1. - С. 108-113.

4. Злоказов К.В. Вопросы развития идентичности в работах последователей Эриксона // Педагогическое образование в России. - 2015. - №9. C. $155-161$.

5. Мякотин И.С. Социальная фобия как нарушение психологических границ и искажение идентичности // Теория и практика общественного развития. 2015. - № 18. - С. 363-365.

6. Никишина В.Б., Лоппас А., Разуваева Т.Н., Петраш Е.A., Запесочкая И.В. Диссоциация образа Я при алкогольной зависимости // Курск. науч.практ. вестн. «Человек и его здоровье». - 2015. № 4. - С. 22-127.

7. Пезешкиан Н. Психосоматика и позитивная психотерапия. - М. : Институт позитивной психотерапии, 2006. -464 с.

8. Никишина В.Б., Запесочкая И.В. Механизмы трансформации состояния зависимости // Вестник Университета (Государственный университет управления). - 2010. - № 17. - С. 83.

9. Никишина В.Б., Петраш Е.А. Методика исследования личностной идентичности: методология и технология стандартизации // Научные ведомости Белгородского государственного университета. Серия: Гуманитарные науки. - 2014. - Т. 21. № 6 (177). - С. 254-261.

10. Петраш Е.A. Нарушение социальной идентичности при зависимости от курительных смесей// Курский научно-практический вестник «Человек и его здоровье» - 2015. - № 1. - С. 125-129.

11. Платонов К.К. О системе психологии. - М. : Мысль, 1972. - 216 с.

12. Руденский Е.В. Психология ненормативного развития личности: Виктимологические основания психологической теории дефицитарной патологии развития личности. - Новосибирск : ГЦРО, 2000. $180 \mathrm{c}$.

13. Суворова И.Ю. Нарушение структуры социальной идентичности в результате социальной эксклюзии // Социальная психология и общество. 2016. - T. 7, № 4. - C. 34-55.

14. Beckwith M., Best D., Lubman D., Dingle G., Perryman $C$. Predictors of flexibility in social identity among people entering a therapeutic community for substance abuse // Alcohol. Treat. -2015. - Vol. 33, N $1 . \quad-\quad$ P. 93-104. $\quad$ - $\quad$ doi: 10.1080/07347324.2015.982465

15. Litt M.D., Kadden R.M., Tennen H. Network Support treatment for alcohol dependence: gender differences in treatment mechanisms and outcomes // Addict. Behav. - 2015. - Vol.45. - P. 87-92. - doi: 10.1016/j.addbeh.2015.01.005

16. Reith $G$. Consumption and its discontents: addiction, identity and the problems of freedom // Br J Sociol. 2004. - Vol. 55, N 2. - P. 283-300. 